\title{
Stock Market Development and Economic Growth an Empirical Analysis
}

\author{
Vazakidis Athanasios and Adamopoulos Antonios
}

Department of Applied Informatics, Faculty of Economics and Social Sciences, University of Macedonia, Greece

\begin{abstract}
This study investigated the causal relationship between stock market development and economic growth for Greece for the period 1978-2007 using a Vector Error Correction Model (VECM). Questions were raised whether stock market development causes economic growth taking into account the negative effect of interest rate on stock market development. The purpose of this study was to investigate the short-run and the long-run relationship between the examined variables applying the Johansen co-integration analysis. To achieve this objective unit root tests were carried out for all time series data in their levels and their first differences. Johansen co-integration analysis was applied to examine whether the variables are cointegrated of the same order taking into account the maximum eigenvalues and trace statistics tests. Finally, a vector error correction model was selected to investigate the long-run relationship between stock market development and economic growth. A short-run increase of economic growth per $1 \%$ induced an increase of stock market index $0.41 \%$ in Greece, while an increase of interest rate per $1 \%$ induced a relative decrease of stock market index per $1.42 \%$ in Greece. The estimated coefficient of error correction term was statistically significant and had a negative sign, which confirmed that there was not any problem in the long-run equilibrium between the examined variables. The results of Granger causality tests indicated that there is a unidirectional causality between stock market development and economic growth with direction from economic growth to stock market development and a unidirectional causal relationship between economic growth and interest rate with direction from economic growth to interest rate. Therefore, it can be inferred that economic growth has a direct positive effect on stock market development while interest rate has a negative effect on stock market development and economic growth respectively.
\end{abstract}

Keywords: Stock Market Development, Economic Growth, VAR Model, Granger Causality

\section{INTRODUCTION}

Stock market development has been the subject of intensive theoretical and empirical studies (DemirgucKunt and Levine, 1996; Levine and Zervos, 1998). More recently, the emphasis has increasingly shifted to stock market indexes and the effect of stock markets on economic development. Stock market contributes to the mobilization of domestic savings by enhancing the set of financial instruments available to savers to diversify their portfolios providing an important source of investment capital at relatively low cost. A well functioning and liquid stock market, that allows investors to diversify away unsystematic risk, will increase the marginal productivity of capital (Pagano, 1993).

Another important aspect through which stock market development may influence economic growth is risk diversification. Obstfeld (1994) suggests that international risk sharing through internationally integrated stock markets improves the allocation of resources and accelerates the process of economic growth.

Fama (1990) and Schwert (1990) claim that there are three explanations for the strong link between stock prices and real economic activity: "First, information

\section{Corresponding Author: Vazakidis Athanasios, Department of Applied Informatics, Faculty of Economics and Social Sciences,} University of Macedonia, Greece 
about future real activity may be reflected in stock prices well before it occurs-this is essentially the notion that stock prices are a leading indicator for the well-being of the economy. Second, changes in discount rates may affect stock prices and real investment similarly, but the output from real investment doesn't appear for some time after it is made. Third, changes in stock prices are changes in wealth and this can affect the demand for consumption and investment goods".

The model hypothesis predicts that economic growth facilitates stock market development taking into account the negative effect of interest rate on stock market development and economic growth.

This study has two objectives:

- To examine the long run relationship among economic growth, interest rate and stock market development

- To apply Granger causality test based on a vector error correction model in order to examine the causal relationships between the examined variables taking into account the Johansen co-integration analysis

The remainder of the study proceeds as follows:

Initially the data and the specification of the multivariate VAR model are described. For this purpose stationarity test and Johansen co-integration analysis are examined taking into account the estimation of vector error correction model.

Finally, Granger causality test is applied in order to find the direction of causality between the examined variables of the estimated model. The empirical results are presented analytically and some discussion issues resulted from this empirical study are developed shortly, while the final conclusions are summarized relatively.

\section{MATERIALS AND METHODS}

\subsection{Data and Specification Model}

In this study the method of Vector Autoregressive Model (VAR) is adopted to estimate the effects of economic growth on stock market development through the effect of interest rate and credit market development. The use of this methodology predicts the cumulative effects taking into account the dynamic response among stock market index and the other examined variables.

In order to test the causal relationships, the following multivariate model is to be estimated as follows (Equation 1):

$$
\mathrm{SM}=\mathrm{f}(\mathrm{GDP}, \mathrm{R})
$$

Where:

$\mathrm{SM}=$ The general stock market index

$\mathrm{R}=$ The interest rate

GDP $=$ The gross domestic product

Following the empirical study of King and Levine (1993) the variable of economic growth (GDP) is measured by the rate of change of real GDP, while the general stock market index is used as a proxy for the stock market development. The general Stock Market index (SM) expresses better the stock exchange market than other financial indices, taking into account the effect of interest Rate (R) (Katos et al., 1996; Nieuwerburgh et al., 2006; Shan, 2005; Vazakidis, 2006; Thalassinos and Thalassinos, 2006; Thalassinos and Pociovalisteanu, 2007; Vazakidis and Adamopoulos, 2009; Adamopoulos, 2010).

The data that are used in this analysis are annual covering the period 1978-2007 for Greece, regarding 2000 as a base year and are obtained from international financial statistics yearbook (IMF, 2007). All time series data are expressed in their levels and Eviews econometric computer software is used for the estimation of the model.

\subsection{Unit Root Tests}

Economic theory does not often provide guidance in determining which variables have stochastic trends and when such trends are common among variables. If these variables share a common stochastic trend, their first differences are stationary and the variables may be jointly co-integrated.

For univariate time series analysis involving stochastic trends, Augmented Dickey and Fuller (1979); Phillips and Perron (1988) and Kwiatkowski et al. (1992) unit root tests are calculated for individual series to provide evidence as to whether the variables are integrated. This is followed by a multivariate co-integration analysis.

Following the study of Seddighi et al. (2000), Augmented Dickey-Fuller (ADF) test involves the estimation one of the following equations (Equation $2 \mathrm{a}, \mathrm{b}, \mathrm{c})$ respectively:

$$
\begin{aligned}
& \Delta \mathrm{X}_{\mathrm{t}}=\beta \mathrm{X}_{\mathrm{t}-1}+\sum_{\mathrm{j}=1}^{\mathrm{p}} \delta_{\mathrm{j}} \Delta \mathrm{X}_{\mathrm{t}-\mathrm{j}}+\varepsilon_{\mathrm{t}} \theta \\
& \Delta \mathrm{X}_{\mathrm{t}}=\alpha_{0}+\beta \mathrm{X}_{\mathrm{t}-1}+\sum_{\mathrm{j}=1}^{\mathrm{p}} \delta_{\mathrm{j}} \Delta \mathrm{X}_{\mathrm{t}-\mathrm{j}}+\varepsilon_{\mathrm{t}}
\end{aligned}
$$




$$
\Delta X_{t}=\alpha_{0}+\alpha_{1} t+\beta X_{t-1}+\sum_{j=1}^{p} \delta_{j} \Delta X_{t-j}+\varepsilon_{t}
$$

The additional lagged terms are included to ensure that the errors are uncorrelated. The maximum lag length begins with 2 lags and proceeds down to the appropriate lag by examining the AIC and SC information criteria.

The null hypothesis is that the variable $X_{t}$ is a nonstationary series $\left(\mathrm{H}_{0}: \beta=0\right)$ and is rejected when $\beta$ is significantly negative $(\mathrm{Ha}: \beta<0)$. If the calculated ADF statistic is higher than McKinnon's critical values, then the null hypothesis $\left(\mathrm{H}_{0}\right)$ is not rejected and the series is non-stationary or not integrated of order zero $\mathrm{I}(0)$. Alternatively, rejection of the null hypothesis implies stationarity. Failure to reject the null hypothesis leads to conducting the test on the difference of the series, so further differencing is conducted until stationarity is reached and the null hypothesis is rejected (Dickey and Fuller, 1979).

In order to find the proper structure of the ADF equations, in terms of the inclusion in the equations of an intercept $\left(\alpha_{0}\right)$ and a trend $(t)$ and in terms of how many extra augmented lagged terms to include in the ADF equations, for eliminating possible autocorrelation in the disturbances, the minimum values of Akaike Information Criterion (AIC) (Akaike, 1973) and Schwarz Criterion (SC) Schwarz (1978) based on the usual Lagrange Multiplier LM(1) test were employed.

Phillips and Perron (1988) test is an extension of the Dickey-Fuller (DF) test, which makes the semiparametric correction for autocorrelation and is more robust in the case of weakly autocorrelation and heteroskedastic regression residuals. According to Choi (1992), the Phillips-Perron test appears to be more powerful than the ADF test for the aggregate data. Although the Phillips-Perron (PP) test gives different lag profiles for the examined variables (time series) and sometimes in lower levels of significance, the main conclusion is qualitatively the same as reported by the Dickey-Fuller (DF) test. Since the null hypothesis in the Augmented Dickey-Fuller test is that a time series contains a unit root, this hypothesis is accepted unless there is strong evidence against it. However, this approach may have low power against stationary near unit root processes.

Following the studies of Chang (2002); Vazakidis and Adamopoulos (2009) and Kwiatkowski et al. (1992) present a test where the null hypothesis states that the series is stationary. The KPSS test complements the Augmented Dickey-Fuller test in that concerns regarding the power of either test can be addressed by comparing the significance of statistics from both tests. A stationary series has significant Augmented DickeyFuller statistics and insignificant KPSS. According to Kwiatkowski et al. (1992), the test of KPSS assumes that a time series can be composed into three components, a deterministic time trend, a random walk and a stationary error based on Equation 3:

$\mathrm{y}_{\mathrm{t}}=\delta \mathrm{t}+\mathrm{r}_{\mathrm{t}}+\varepsilon_{\mathrm{t}}$

where, $r_{t}$ is a random walk $r_{t}=r_{t-1}+u_{t .}$. The $u_{t}$ is iid $\left(0,0, \sigma_{u}^{2}\right)$. The stationarity hypothesis implies that $\sigma_{u}^{2}=0$.

Under the null, $\mathrm{y}_{\mathrm{t}}$, is stationary around a constant $(\delta=0)$ or trend-stationary $(\delta \neq 0)$. In practice, one simply runs a regression of $y_{t}$ over a constant (in the case of level-stationarity) ore a constant plus a time trend (in the case of trend-stationary). Using the residuals, $\mathrm{e}_{\mathrm{i}}$, from this regression, one computes the LM statistic as follows (Equation 3a, b):

$\mathrm{LM}=\mathrm{T}^{-2} \sum_{\mathrm{t}=1}^{\mathrm{T}} \mathrm{S}_{\mathrm{t}}^{2} / \mathrm{S}_{\mathrm{\varepsilon t}}^{2}$

where, $S_{\varepsilon t}^{2}$ is the estimate of variance of $\varepsilon_{t}$ :

$\mathrm{S}_{\mathrm{t}}=\sum_{\mathrm{i}=1}^{\mathrm{t}} \mathrm{e}_{\mathrm{i}}, \mathrm{t}=1,2, \ldots \ldots \mathrm{T}$

The distribution of LM is non-standard: The test is an upper tail test and limiting values are provided by Kwiatkowski et al. (1992), via Monte Carlo simulation. To allow weaker assumptions about the behavior of $\varepsilon_{\mathrm{t}}$, one can rely, following Phillips (1987) on the Newey and West (1987) estimate of the long-run variance of $\varepsilon_{t}$ which is defined as follows (Equation $3 \mathrm{c}, \mathrm{d}$ ):

$\mathrm{S}^{2}(1)=\mathrm{T}^{-1} \sum_{\mathrm{t}=1}^{\mathrm{T}} \mathrm{e}_{\mathrm{i}}^{2}+2 \mathrm{~T}^{-1} \sum_{\mathrm{s}=1}^{1} \mathrm{w}(\mathrm{s}, 1) \sum_{\mathrm{t}=\mathrm{s}+1}^{\mathrm{T}} \mathrm{e}_{\mathrm{i}} \mathrm{e}_{\mathrm{i}-\mathrm{k}}$

where, $\mathrm{w}(\mathrm{s}, \mathrm{l})=1-\mathrm{s} /(1+1)$. In this case the test becomes:

$v=\mathrm{T}^{-2} \sum_{\mathrm{t}=1}^{\mathrm{T}} \mathrm{S}_{\mathrm{t}}^{2} / \mathrm{S}^{2}(1)$ 
Table 1. Tests of unit roots hypothesis

Phillips-Perron

PP_test stat

Augmented Dickey-Fuller

\begin{tabular}{llllrrll}
\hline Greece & ADF_test stat & lag eq_f & $\mathrm{t}_{\mathrm{n}}$ & $\mathrm{t}_{\mathrm{c}}$ & $\mathrm{t}_{\mathrm{t}}$ & $\mathrm{h}_{\mathrm{c}}$ & \\
\hline $\mathrm{SM}$ & $3.64(0.04)$ & $\mathrm{p}=1(4)$ & $2.42(0.99)$ & $1.12(0.99)$ & $-0.95(0.93)$ & $0.65^{* * *}$ & $\mathrm{~h}_{\mathrm{t}}$ \\
$\mathrm{R}$ & $-2.49(0.32)$ & $\mathrm{p}=1(4)$ & $-0.69(0.4)$ & $-0.88(0.77)$ & $-2.23(0.45)$ & $0.41^{* * *}, * *$ & $0.15^{* * *}$ \\
GDP & $13.45(1.00)$ & $\mathrm{p}=0(2)$ & $13.45(1.00)$ & $6.25(1.00)$ & $1.99(1.00)$ & $0.68^{* * *}$ & $0.18^{* * *}$ \\
$\Delta \mathrm{SM}$ & $-3.02(0.003)$ & $\mathrm{p}=0(2)$ & $-2.56(0.01)$ & $-2.64(0.09)$ & $-2.90(0.17)$ & 0.32 & $0.19^{* * * *}$ \\
$\Delta \mathrm{R}$ & $-3.46(0.001)$ & $\mathrm{p}=1(2)$ & $-3.45(0.001)$ & $-3.40(0.01)$ & $-3.62(0.04)$ & 0.28 & 0.09 \\
$\Delta \mathrm{GDP}$ & $-3.98^{* * *}(0.02)$ & $\mathrm{p}=0(4)$ & $-0.26(0.58)$ & $-1.84(0.35)$ & $-3.98(0.02)$ & $0.57^{* *}, *$ & $0.14^{*}$ \\
\hline
\end{tabular}

Notes: The calculated statistics are those reported. The critical values for R, SM and $\Delta$ GDP at 1,5 and $10 \%$ are $-4.32,-3.58,-3.22$, for GDP, at 1,5 and $10 \%$ are $-2.62,-1.95,-1.61$ for $\Delta \mathrm{SM}, \Delta \mathrm{R}$ at 1,5 and $10 \%$ are $-2.65,-1.95,-1.60$ respectively; The lag-length (p) structure of $a_{I}$ of the dependent variable $x_{t}$ is determined using the recursive procedure in the light of a Langrange Multiplier (LM) autocorrelation test (for orders up to four), which is asymptotically distributed as chi-squared distribution and the value t-statistic of the coefficient associated with the last lag in the estimated autoregression; The critical values for the Phillips-Perron unit root tests are obtained $t_{n}, t_{c}$ and $t_{t}$ are the PP statistics for testing the null hypothesis the series are not $I(0)$ when the residuals are computed from a regression equation without an intercept and time trend, with only an intercept and with both intercept and time trend, respectively. The critical values at 1,5 and $10 \%$ are $-2.62,-1.94,-1.61$, for $t_{n},-3.60,-2.93,-2.60$ for $t_{t}$ and for $-4.19,-3.52,-3.19$ for $\mathrm{t}_{\tau}$ respectively; $\mathrm{k}=$ bandwidth length: Newey-West using Bartlett kernel; $h_{c}$ and $h_{t}$ are the KPSS statistics for testing the null hypothesis that the series are $\mathrm{I}(0)$ when the residuals are computed from a regression equation with only an intercept and intercept and time trend, respectively. The critical values at $1 \%, 5 \%$ and $10 \%$ are $0.73,0.46$ and 0.34 for $h_{c}$ and $0.21,0.14$ and 0.11 for $h_{t}$ respectively (Kwiatkowski et al., 1992, Table 1); Since the value of the test will depend upon the choice of the 'lag truncation parameter', 1; 1 = B and width length: Newey-West using Bartlett kernel; ***, ** and *: Indicate that those values are not consistent with relative hypotheses at the $1 \%, 5 \%$ and $10 \%$ levels of significance relatively

Which is the one considered here. Obviously the value of the test will depend upon the choice of the 'lag truncation parameter', 1. Here we use the sample autocorrelation function of $\Delta \mathrm{e}_{\mathrm{t}}$ to determine the maximum value of the lag length 1) statistics.

The KPSS statistic tests for a relative lag-truncation parameter (1), in accordance with the default Bartlett kernel estimation method (since it is unknown how many lagged residuals should be used to construct a consistent estimator of the residual variance), rejects the null hypothesis in the levels of the examined variables for the relative lag-truncation parameter (1).

The econometric software Eviews which is used to conduct the ADF, PP, KPSS tests, reports the simulated critical values based on response surfaces. The results of the ADF, PP, KPSS tests for each variable appear in Table 1. If the time series (variables) are non-stationary in their levels, they can be integrated with integration of order 1 , when their first differences are stationary.

\subsection{Johansen Co-Integration Analysis}

Following the studies of Chang (2002) and Vazakidis and Adamopoulos (2009), since it has been determined that the variables under examination are integrated of order 1, then the co-integration test is performed. The testing hypothesis is the null of non-co-integration against the alternative that is the existence of cointegration using the Johansen maximum likelihood procedure (Johansen and Juselius, 1990; 1992).

According to Chang and Caudill (2005) once a unit root has been confirmed for a data series, the question is whether there exists a long-run equilibrium relationship among variables. According to Engle and Granger (1987), a set of variables, $Y_{t}$ is said to be co-integrated of order $(d, b)$-denoted $\mathrm{CI}(\mathrm{d}, \mathrm{b})$-if $\mathrm{Y}_{\mathrm{t}}$ is integrated of order $d$ and there exists a vector, $\beta$, such that $\beta^{\prime} Y_{t}$ is integrated of order (d-b). Co-integration tests in this study are conducted using the method developed by Johansen (1988) and Johansen and Juselius (1990).

The multivariate co-integration techniques developed by Johansen (1988) and Johansen and Juselius (1990) using a maximum likelihood estimation procedure allows researchers to estimate simultaneously models involving two or more variables to circumvent the problems associated with the traditional regression methods used in previous studies on this issue. Therefore, the Johansen method applies the maximum likelihood procedure to determine the presence of cointegrated vectors in nonstationary time series. 
Following the study of Chang and Caudill (2005); Johansen (1988) and Johansen and Juselius (1990) propose two test statistics for testing the number of cointegrated vectors (or the rank of $\Pi$ ) the trace $\left(\lambda_{\text {trace }}\right)$ and the maximum eigenvalue $\left(\lambda_{\max }\right)$ statistics.

The likelihood Ratio Statistic (LR) for the trace test ( $\left.\lambda_{\text {trace}}\right)$ as suggested by Johansen (1988) is presented in Equation 4a:

$$
\lambda_{\text {trace }}(\mathrm{r})=-\mathrm{T} \sum_{\mathrm{i}=\mathrm{r}+1}^{\mathrm{p}} \ln \left(1-\widehat{\lambda}_{\mathrm{i}}\right)
$$

Where:

$$
\begin{aligned}
\hat{\lambda}_{\mathrm{i}}= & \text { The largest estimated value of ith characteristic } \\
& \text { root (eigenvalue) obtained from the estimated } \Pi \\
& \text { matrix, } \mathrm{r}=0,1,2, \ldots \ldots \mathrm{p}-1 \\
\mathrm{~T}= & \text { The number of usable observations }
\end{aligned}
$$

The $\lambda_{\text {trace }}$ statistic tests the null hypothesis that the number of distinct characteristic roots is less than or equal to $r$, (where $r$ is 0,1 , or 2) against the general alternative. In this statistic $\lambda_{\text {trace }}$ will be small when the values of the characteristic roots are closer to zero (and its value will be large in relation to the values of the characteristic roots which are further from zero).

Alternatively, the maximum eigenvalue $\left(\lambda_{\max }\right)$ statistic as suggested by Johansen is presented in Equation 4b:

$$
\lambda_{\max }(\mathrm{r}, \mathrm{r}+1)=-\mathrm{T} \ln \left(1-\hat{\lambda}_{\mathrm{r}+1}\right)
$$

The $\lambda_{\max }$ statistic tests the null hypothesis that the number of $r$ co-integrated vectors is $r$ against the alternative of $(\mathrm{r}+1)$ co-integrated vectors. Thus, the null hypothesis $r=0$ is tested against the alternative that $r=$ $1, r=1$ against the alternative $r=2$ and so forth. If the estimated value of the characteristic root is close to zero, then the $\lambda_{\max }$ will be small.

It is well known that Johansen's co-integration tests are very sensitive to the choice of lag length. Firstly, a VAR model is fitted to the time series data in order to find an appropriate lag structure. The Schwarz Criterion (SC) and the Likelihood Ratio (LR) test are used to select the number of lags required in the co-integration test. The Schwarz Criterion (SC) and the Likelihood Ratio (LR) test suggested that the value $p=3$ is the appropriate

\begin{tabular}{|c|c|c|c|c|}
\hline \multirow{3}{*}{$\begin{array}{l}\text { Testing } \\
\text { hypothesis }\end{array}$} & \multicolumn{4}{|c|}{ Country: Greece } \\
\hline & \multicolumn{4}{|c|}{ Johansen test statistics } \\
\hline & \multirow[t]{3}{*}{$\lambda_{\text {trace }}$} & \multirow{3}{*}{$\begin{array}{c}\mathrm{Cr}_{-} \mathrm{V} \\
5.00 \% \\
1.00 \%\end{array}$} & \multirow[t]{3}{*}{$\lambda_{\max }$} & Cr_v \\
\hline & & & & $5.00 \%$ \\
\hline & & & & $1.00 \%$ \\
\hline \multirow[t]{2}{*}{$\mathrm{H}_{0}: \mathrm{r}=0$ and $\mathrm{r}=1$} & \multirow[t]{2}{*}{32.590} & 24.31 & 21.050 & 17.89 \\
\hline & & 29.75 & & 22.99 \\
\hline \multirow[t]{2}{*}{$\mathrm{H}_{0}: \mathrm{r} £ 1$ and $\mathrm{r}=2$} & \multirow[t]{2}{*}{11.530} & 12.53 & 10.530 & 11.44 \\
\hline & & 16.31 & & 15.69 \\
\hline \multirow[t]{2}{*}{$\mathrm{H}_{0}: \mathrm{r} £ 2$ and $\mathrm{r}=3$} & \multirow[t]{2}{*}{1.006} & 3.84 & 1.006 & 3.84 \\
\hline & & 6.51 & & 6.51 \\
\hline
\end{tabular}
specification for the order of VAR model for Greece.

Table 2 shows the results from the Johansen cointegration test.
Table 2. Johansen and Juselius co-integration tests (SM, GDP, R)

Co-integrated vectors1 (for 1 and 5\%)

Note: $\mathrm{Cr} \_\mathrm{v}=$ Critical values

Table 3. Vector error correction model

\begin{tabular}{lr}
\hline Dependent variable $(\Delta \mathrm{SM})$ & Estimated coefficients \\
\hline Constant & $-0.0019[0.9545]$ \\
$\Delta \mathrm{GDP}_{\mathrm{t}-3}$ & $0.4132[0.5568]$ \\
$\Delta \mathrm{SM}_{\mathrm{t}-1}$ & $0.6043[0.0013]$ \\
$\Delta \mathrm{R}_{\mathrm{t}-2}$ & $-1.4226[0.1428]$ \\
$\mathrm{ECT}$ & $-0.5968[0.0002]$ \\
$\mathrm{R}^{2}$ & 0.6091 \\
$\mathrm{DW}$ & 2.1934 \\
Diagnostics tests & \\
Serial correlation & $0.7041[0.401]$ \\
Functional form & $0.0616[0.804]$ \\
Normality & $77.7055[0.000]$ \\
Heteroscedasticity & $0.1684[0.682]$ \\
\hline [ ] $=$ I denote the probability levels; $\Delta:$ Denotes the first \\
differences of the variables; $\mathrm{R}^{2}=$ Coefficient of multiple \\
determinations adjusted for the degrees of freedom (d.f); DW \\
$=$ Durbin-Watson statistic
\end{tabular}

Table 4. Pairwise Granger causality tests Sample: 1978-2007: Lags: 2

\begin{tabular}{lcc} 
Null hypothesis & f-statistic & Probability \\
\hline GDP does not Granger cause SM & 11.6152 & {$[0.0003]$} \\
SM does not Granger cause GDP & 0.0280 & {$[0.9723]$} \\
R does not Granger cause SM & 2.2425 & {$[0.1288]$} \\
SM does not Granger cause R & 1.4476 & {$[0.2557]$} \\
R does not Granger cause GDP & 2.3135 & {$[0.1214]$} \\
GDP does not Granger cause R & 3.8887 & {$[0.0350]$} \\
\hline
\end{tabular}

\subsection{Vector Error Correction Model}

According to Chang and Caudill (2005) since the variables included in the VAR model are found to be cointegrated, the next step is to specify and estimate a Vector Error Correction Model (VECM) including the error correction term to investigate dynamic behavior of 
the model. Once the equilibrium conditions are imposed, the VEC model describes how the examined model is adjusting in each time period towards its long-run equilibrium state.

Since the variables are co-integrated, then in the short run, deviations from this long-run equilibrium will feed back on the changes in the dependent variables in order to force their movements towards the long-run equilibrium state. Hence, the co-integrated vectors from which the error correction terms are derived are each indicating an independent direction where a stable meaningful long-run equilibrium state exists.

The VEC specification forces the long-run behavior of the endogenous variables to converge to their cointegrated relationships, while accommodates short-run dynamics. The dynamic specification of the model allows the deletion of the insignificant variables, while the error correction term is retained. The size of the error correction term indicates the speed of adjustment of any disequilibrium towards a long-run equilibrium state (Engle and Granger, 1987). The error-correction model with the computed t-values of the regression coefficients in parentheses is reported in Table 3.

The final form of the Error-Correction Model (ECM) was selected according to the approach suggested by Hendry (Maddala, 1992). Following the study of Chang (2002) the general form of the Vector Error Correction Model (VECM) is presented in Equation 5:

$$
\begin{aligned}
\Delta \mathrm{Y}_{\mathrm{t}} & =\beta_{1} \sum_{\mathrm{i}}^{\mathrm{n}} \Delta \mathrm{Y}_{\mathrm{t}-\mathrm{i}}+\beta_{2} \sum_{\mathrm{i}}^{\mathrm{n}} \Delta \mathrm{X}_{\mathrm{t}-\mathrm{i}} \\
& +\beta_{3} \sum_{\mathrm{i}}^{\mathrm{n}} \Delta \mathrm{Z}_{\mathrm{t}-\mathrm{i}}+\lambda \mathrm{EC}_{\mathrm{t}-\mathrm{i}}+\varepsilon_{\mathrm{t}}
\end{aligned}
$$

Where:

$\Delta=$ The first difference operator

$\mathrm{EC}_{\mathrm{t}-1}=$ The error correction term lagged one period

$\lambda=$ The short-run coefficient of the error correction term $(-1<\lambda<0)$

$\varepsilon_{\mathrm{t}} \quad=$ The white noise term

\subsection{Granger Causality Tests}

Granger causality is used for testing the long-run relationship between stock market development and economic growth. The Granger procedure is selected because it consists the more powerful and simpler way of testing causal relationship (Granger, 1986). The following bivariate model is estimated as follows:

$$
Y_{t}=a_{10}+\sum_{j=1}^{k} a_{1 j} Y_{t-j}+\sum_{j=1}^{k} b_{1 j} X_{t-j}+u_{t}
$$

$$
X_{t}=a_{20}+\sum_{j=1}^{k} a_{2 j} X_{t-j}+\sum_{j=1}^{k} b_{2 j} Y_{t-j}+u_{t}
$$

Where:

$\mathrm{Y}_{\mathrm{t}}=$ The dependent

$X_{t}=$ The explanatory variable

$\mathrm{u}_{\mathrm{t}}=$ A zero mean white noise error term in Equation 6 while

$X_{t}=$ The dependent

$\mathrm{Y}_{\mathrm{t}}=$ The explanatory variable in Equation 7

In order to test the above hypotheses the usual Wald F-statistic test is utilized, which has the following form:

$F=\frac{\left(\operatorname{RSS}_{\mathrm{R}}-\mathrm{RSS}_{\mathrm{U}}\right) / \mathrm{q}}{\mathrm{RSS}_{\mathrm{U}} /(\mathrm{T}-2 \mathrm{q}-1)}$

Where:

$\mathrm{RSS}_{\mathrm{U}}=$ The sum of squared residuals from the complete (unrestricted) equation

$\mathrm{RSS}_{\mathrm{R}}=$ The sum of squared residuals from the equation under the assumption that a set of variables is redundant, when the restrictions are imposed, (restricted equation)

$\mathrm{T}=$ The sample size

$\mathrm{q}=$ is the lag length

According to Seddighi et al. (2000) and Katos (2004) the hypotheses in this test are the following (Equation 8 and 9):

$\mathrm{H}_{0}$ : $\mathrm{X}$ does not Granger cause $\mathrm{Y}$, i.e.,

$\left\{\alpha_{11}, \alpha_{12}, \ldots \ldots \alpha_{1 k}\right\}=0$, if $F_{c}<$ critical value of $F$

$\mathrm{H}_{\mathrm{a}}: \mathrm{X}$ does Granger cause $\mathrm{Y}$, i.e.,

$\left\{\alpha_{11}, \alpha_{12}, \ldots \ldots \alpha_{1 \mathrm{k}}\right\} \neq 0$, if $\mathrm{F}_{\mathrm{c}}>$ critical value of $\mathrm{F}$

And:

$\mathrm{H}_{0}$ : Y does not Granger cause $X$, i.e., $\left\{\beta_{21}, \beta_{22}, \ldots \beta_{2 \mathrm{k}}\right\}$

$=0$, if $\mathrm{F}_{\mathrm{c}}<$ critical value of $\mathrm{F}$

$\mathrm{H}_{\mathrm{a}}$ : Y does Granger cause $\mathrm{X}$, i.e., $\left\{\beta_{21}, \beta_{22}, \ldots . \beta_{2 \mathrm{k}}\right\}$

$\neq 0$, if $F_{c}>$ critical value of $F$

The results related to the existence of Granger causal relationships among economic growth, stock market development and interest rate appear in Table 4.

\section{RESULTS}

The observed t-statistics fail to reject the null hypothesis of the presence of a unit root for all variables 
in their levels confirming that they are non-stationary at 1,5 and $10 \%$ levels of significance but when they are transformed into their first differences become stationary and integrated of the same order (Table 1). Therefore, the combined results (ADF, PP, KPSS) from all tests can be characterized as integrated of order one, I(1).

These variables can be co-integrated as well, if there are one or more linear combinations among the variables that are stationary. The results that appear in Table 2 suggest that the number of statistically significant cointegrated vectors for Greece is equal to 1 (Table 2) and is the following one in (Equation 5a):

$\mathrm{SM}=1.06 \mathrm{GDP}-1.24 \mathrm{R}$

The co-integrated vector of the model of Greece presented in Table 2 has rank $r<p(p=2)$. The process of estimating the rank $r$ is related with the assessment of eigenvalues, which are the following for Greece: $\hat{\lambda}_{1}=0.5414, \hat{\lambda}_{2}=0.3230$ and $\hat{\lambda}_{3}=0.3230$.

For Greece, critical values for the trace statistic defined by Equation $4 \mathrm{a}$ are 24.31 and 29.75 for $\mathrm{H}_{0}: \mathrm{r}$ $=0$ and 12.53 and 16.31 for $H_{0}: r \leq 1,3.84$ and 6.51 for $\mathrm{H}_{0}: \mathrm{r} \leq 2$ at the significance level 5 and $1 \%$ respectively as reported by Osterwald-Lenum (1992), while critical values for the maximum eigenvalue test statistic defined by Equation $4 \mathrm{~b}$ are 17.89 and 22.99 for $\mathrm{H}_{0}: \mathrm{r}=0$, 11.44 and 15.69 for $H_{0}: r \leq 1,3.84$ and 6.51 for $H_{0}: r \leq 2$.

It is obvious from the above co-integrated vector that economic growth has a positive effect on stock market development in the long-run, while interest rate has a negative effect on stock market development. According to the signs of the vector co-integration components and based on the basis of economic theory the above relationships can be used as an error correction mechanism in a VAR model for Greece respectively.

The error-correction model with the computed $\mathrm{t}$ values of the regression coefficients in parentheses is reported in Table 3. The dynamic specification of the model allows the deletion of the insignificant variables, while the error correction term is retained.

From the results of Table 3 we can see that a shortrun increase of economic growth per $1 \%$ induces an increase of stock market index per $0.41 \%$ in Greece, while an increase of interest rate per $1 \%$ induces a decrease of stock market index per $1.42 \%$ in Greece.

The estimated coefficient of $\mathrm{EC}_{\mathrm{t}-1}$ is statistically significant and has a negative sign, which confirms that there is not any problem in the long-run equilibrium relation between the independent and dependent variables in $5 \%$ level of significance, but its relatively value $(-0.596)$ for Greece shows a satisfactory rate of convergence to the equilibrium state per period (Table 3). From the above results the VAR model in which stock market development is examined as a dependent variable has obtained the best statistical estimates. In order to proceed to the Granger causality test the number of appropriate time lags was selected in accordance with the VAR model.

According to Granger causality tests there is a unidirectional causality between stock market development and economic growth with direction from economic growth to stock market development and a unidirectional causal relationship between economic growth and interest rate with direction from economic growth to interest rate (Table 4).

\section{DISCUSSION}

The model of stock market development is mainly characterized by the effect of economic growth and interest rate. Stock market development is determined by the trend of general stock market index. The significance of the empirical results is dependent on the variables under estimation.

Most empirical studies examine the causal relationship between stock market development and economic growth using different estimation financial measures like stock market capitalization, stock market liquidity and general stock market index.

Granger causality test is the more powerful causality test based on the methodology of vector error correction model in relation to other causality tests like Geweke, Sims, Toda and Yamamoto.

Theory provides conflicting aspects for the direction of causality between stock market development and economic growth. Most empirical studies suggested that there is a unidirectional causality between stock market development and economic growth with direction from stock market development to economic growth, while less empirical studies have found bilateral causality between economic growth and stock market development or unidirectional causality with direction from economic growth to stock market development.

The results of this study are agreed with the studies of Levine and Zervos (1998) and Shan (2005). Therefore the direction of causal relationship between stock market development and economic growth is regarded as an important issue under consideration in future empirical 
studies. However, more interest should be focused on the comparative analysis of empirical results for the rest of European Union members-states using different estimation measures and causality estimation methods.

\section{CONCLUSION}

This study employs with the relationship between financial development and economic growth for Greece, using annually data for the period 1978-2007. The empirical analysis suggested that the variables that determine economic growth present a unit root. Once a co-integrated relationship among relevant economic variables is established, the next issue is how these variables adjust in response to a random shock. This is an issue of the short-run disequilibrium dynamics.

The short run dynamics of the model is studied by analyzing how each variable in a co-integrated system responds or corrects itself to the residual or error from the cointegrating vector. This justifies the use of the term error correction mechanism. The Error Correction (EC) term, picks up the speed of adjustment of each variable in response to a deviation from the steady state equilibrium. The VEC specification forces the long-run behavior of the endogenous variables to converge to their cointegrating relationships, while accommodates the shortrun dynamics. The dynamic specification of the model suggests deletion of the insignificant variables while the error correction term is retained. Economic growth has a direct positive effect on stock market development while interest rate has a negative effect on stock market development and economic growth respectively.

The results of Granger causality tests indicated that there is a unidirectional causality between stock market development and economic growth with direction from economic growth to stock market development and a unidirectional causal relationship between economic growth and interest rate with direction from economic growth to interest rate.

\section{REFERENCES}

Adamopoulos, A., 2010. Financial development and economic growth: A comparative study between 15 European Union member-states. Int. Res. J. Finance Econ., 35: 144-149.

Akaike, H., 1973. Information theory and an extension of the maximum likelihood principle. Proceedings of the 2nd International Symposium on Information Theory, Akademiai Kiado, Budapest.
Chang, T. and S. Caudill, 2005. Financial development and economic growth: The case of Taiwan. Applied Econ., 37 : 1329-1335. DOI: $10.1080 / 0003684042000338702$

Chang, T., 2002. An econometric test of Wagner's law for six countries based on cointegration and errorcorrection modelling techniques. Applied Econ., 34: 1157-1169.

Choi, I., 1992. Effects of data aggregation on the power of tests for a unit root: A simulation study. Econ. Lett., 40: 397-401.

Demirguc-Kunt, A. and R. Levine, 1996. Stock markets, corporate finance, and economic growth: An overview. World B. Econ. Rev., 10: 223-239.

Dickey, D. and W. Fuller, 1979. Distribution of the estimators for autoregressive time series with a unit root. J. Am. Stat. Assoc., 74: 427-431.

Engle, R. and C. Granger, 1987. Co-integration and error correction: Representation, estimation, and testing. Econometrica, 55: 251-276.

Fama, E.F., 1990. Stock returns, expected returns, and real activity. J. Finance, 45: 1089-1108. DOI: 10.1111/j.1540-6261.1990.tb02428.x

Granger, C., 1986. Developments in the study of cointegrated economic variables. Oxford Bull. Econ. Stat., 48: 213-228.

IMF, 2007. International Financial Statistics Yearbook. 1st Edn., Various Years, Washington DC., USA., pp: 205.

Johansen, S. and K. Juselius, 1990. Maximum likelihood estimation and inference on cointegration-with applications to the demand for money. Oxford Bull. Econ. Stat., 52: 169-210. DOI: $10.1111 / \mathrm{j} .1468-$ 0084.1990.mp52002003.x

Johansen, S. and K. Juselius, 1992. Testing Structural Hypotheses in a Multivariate Cointegration Analysis of the PPP and the UIP for UK. J. Econ., 53: 211-244.

Johansen, S., 1988. Statistical analysis of cointegration vectors. J. Econ. Dyn. Control, 12: 231-254.

Katos, A., 2004. Econometrics: Theory and Practice. 1st Edn., Zygos, Thessaloniki, pp: 1200.

King, R. and R. Levine, 1993. Finance and growth: Schumpeter might be right. Q. J. Econ., 108: 717-737.

Kwiatkowski, D., P. Phillips, P. Schmidt and Y. Shin, 1992. Testing the null hypothesis of stationarity against the alternative of a unit root: How sure are we that economic time series have a unit root? J. Econometr., 54: 159-178.

Levine, R. and S. Zervos, 1998. Stock markets, banks, and economic growth. Am. Econ. Rev., 88: 537-558.

Maddala, G.S., 1992. Introduction to Econometrics. 2nd Edn., Prentice-Hall International, London, ISBN10: 0023745452 , pp: 631 . 
Newey, W. and K. West, 1987. A simple, positive semidefinite, heteroskedasticity and autocorrelation consistent covariance matrix. Econometrica, 55: 703-708.

Nieuwerburgh, S., F. Buelens and L. Cuyvers, 2006. Stock market development and economic growth in Belgium. Explor. Econ. History, 43: 13-38. DOI: 10.1016/j.eeh.2005.06.002

Obstfeld, M., 1994. Risk-taking, global diversification, and growth. Am. Econ. Rev., 84: 1310-1329.

Osterwald-Lenum, M., 1992. A Note with quantiles of the asymptotic distribution of the maximum likelihood cointegration rank test statistics. Oxford Bull. Econ. Stat., 54: 461-472.

Pagano, M., 1993. Financial markets and growth: An overview. Eur. Econ. Rev., 37: 613-622.

Phillips, P. and P. Perron, 1988. Testing for a unit root in time series regression. Biometrika, 75: 335-346. DOI: $10.1093 /$ biomet $/ 75.2 .335$

Phillips, P., 1987. Time series regression with a unit root. Econometrica, 2: 277-301.

Schwarz, R., 1978. Estimating the dimension of a model. Ann. Stat., 6: 461-464.
Schwert, W., 1990. Stock returns and real activity: A century of evidence. J. Finance, 45: 1237-1257.

Seddighi, H., K.A. Lawler and A.V. Katos, 2000. Econometrics: A Practical Approach, 1st Edn., Routledge, London, ISBN-10: 0415156459, pp: 396.

Shan, J., 2005. Does financial development 'lead' economic growth? A vector auto-regression appraisal. Applied Econ., 37: 1353-1367.

Thalassinos, E. and D. Pociovalisteanu, 2007. A time series model for the Romanian stock market. Eur. Res. Stud., 10: 57-72.

Thalassinos, E. and P. Thalassinos, 2006. Stock markets' integration analysis. Eur. Res. Stud., 9: 313.

Vazakidis, A. and A. Adamopoulos, 2009. Credit market development and economic growth. Am. J. Econ. Bus. Admin., 1: 34-40.

Vazakidis, A., 2006. Testing simple versus dimson market models: The case of the athens stock exchange. Int. Res. J. Finance Econ., 2: 26-34.

Katos, A., G. Pekos, E. Katsouli and C. Batzios, 1996. Saving-investment equilibrium in the European Union: An economic policy exercise. Riv. Int. Sci. Econ. Com., 43: 81-107. 